SHS Web of Conferences 24, 02017 (2016)

DOI: $10.1051 /$ shsconf/20162402017

(c) Owned by the authors, published by EDP Sciences, 2016

\title{
Analysis on factors of affecting the status of physical education in Chinese school
}

\author{
Chengquan Jin* \\ Country Physical Education Department of Henan Agricultural University, Zhengzhou, Henan, China
}

\begin{abstract}
Focusing on the current marginalized status of school physical education in Chinese school education, using the method of literature, interview and investigation, this paper from the perspective of sociology analyzed the affecting factors of status of school physical education in our country and hoped to provide reference for the reform and development of school physical education and school education. The results showed much attention of government administration and school leaders paying to physical education, the impact of China's traditional culture, social recognition to the profession of PE teachers, students' understanding of the importance of physical education class and other factors that determined the status of Chinese school physical education.
\end{abstract}

Keywords: school physical education; physical education; education

\section{INTRODUCTION}

As the basis of Chinese sports, school physical education is an important part of school education and an important aspect of cultivating the personnel of socialist construction with all of development of moral, brain, body and so on. Orderly and effective conduct of school physical education plays a decisive role in improving the physical fitness of young people as well as all citizens, developing sport habits and cultivating lifelong sports consciousness. Therefore, the educational experts and the government department of education have paid more attention on school physical education. And that how to make school physical education embark on the scientific and standardized track and fully play the role in the process of shaping high-qualified personnel to meet the current needs of social development and quality education is also a subject continuously explored by the personage in education and physical education field. But in reality, Chinese school physical education has been in the awkward position of being marginalized, which seriously deviates from the attention of national educational departments and experts. The reason of this consequence is thought-provoking. From the perspective of sociology, this paper strives to objectively analyse the main reasons of influencing the status of

*Corresponding author: 441520737@qq.com school physical education as an social activities, in order to contribute own power for the exploration and research of promoting the sound operation and coordinated development of school physical education.

\section{THE CURRENT STATUS OF SCHOOL PHYSICAL EDUCATION IN CHINA}

\subsection{National attention on school physical education}

The status of school physical education in school education in China was established in 1903. At that time, the "constitution of school" was issued by Qing government, which had stipulated that various types of schools at all levels should set up gymnastics curriculum. This provision had made the modern school physical education universally implemented and ended the history that Chinese school education had basically no physical education over two thousand years [1] After more than one hundred years of development, the guiding ideology of Chinese school physical education have been matured and the teaching materials, teaching methods and various teaching systems have also been constantly perfected. And the importance of school physical education had been generally understood and accepted. Especially since our country followed the policy of reform and opening, the national 


\section{SHS Web of Conferences}

education department had provided a series of institutional guarantee in order to ensure the smooth development of school physical education. Under this background, China's school physical education has gone back on the right track. In October 1979, the ministry of education and national sports commission jointly issued The Temporary Provisions on the Work of Higher School Physical Education (draft) and The Temporary Provisions on the Work of the Primary and Middle School Physical Education (draft). On the basis of that the drafts had been enforced for ten years, the state council promulgated Rules and Regulations of the Work of School Physical Education on March 12,1990 , which prescribed that all grades of ordinary primary and secondary schools, agricultural middle schools, vocational middle school, secondary specialized school and the first, second grade of general higher academy must offer physical education curriculum and clearly put forward that punitive measures should be adopted to the phenomenon of violating regulations. Rules and Regulations of School Physical Education established the status of school physical education on the system. On August 29, 1995, The Fifth Standing Committee Session of the Eleventh National People's Congress had passed Sports Law of the People's Republic of China, which determined that schools must offer physical education and ensure physical exercise time of students in the form of law. With the implementation of the education reform in our country, school physical education has been paid close attention again. On June 13, 1999, the Central Committee of the Communist Party of China and the State Council issued Decision on Deepening Education Reform and Comprehensively Promoting Quality Education which pointed out that healthy body which is the basic premise of adolescent servicing for the motherland and the people is a manifestation of the strong vitality of China. So school education must set up the guiding ideology of health at first and strengthen the work of physical education in order to enable students to master basic sports skills and form good habit of exercise the body. This prompted that people paid more attention to the function and significance of the school physical education. After entering the new century, according to the condition of the decline of students' physique, the State Council and the Ministry of Education respectively issued The Proposal of Implementing the Guarantee of Primary and Secondary School Students' Time of Physical Education Every Day and The Proposal of Strengthening Teenagers' Physical Education in order to Improve Teenagers' Physique in 2005 and 2007. These documents of laws and regulations fully embodied the country attaches great importance to the school physical education.

\subsection{The actual status of school physical education}

Unfortunately, the attention of the state and the educa- tion department does not really improve the realistic status of school physical education in school education, which was also reflected in the file of the Ministry of Education. The Proposal of Implementing the Guarantee of Primary and Secondary School Students Time of Physical Education Every Day pointed out: "The results of 2004 National Student Physical Health Monitoring show that part of primary and middle school students' body quality in China, especially explosive force, physical strength, endurance quality and vital capacity index continues to decline, the proportion of overweight and obesity students increase and the detection rate of students' poor vision continues to rise. The reasons for these problems are various, but the main reason is that the time of students' everyday physical exercise and sports activities cannot be guaranteed. The Rules and Regulations of the Work of School Physical Education requires primary and secondary schools to ensure that student have an hour doing physical exercises every day. But for a long time, the rules were always failed to cause the attention of some locals and schools and, the requirement of the students of doing physical exercises one hour per day has not been implemented ${ }^{[2]}$." When referring to the deterioration of adolescent physical, The Proposal of Strengthening Youth Physical Education in order to Improve Teenagers' Physique also mentioned, "On one hand, because of the influence of the one-sided pursuit of graduation rates, society and school have the tendency of attaching great importance to intellectual education and paying little attention to physical education, and school students' academic burden is overweight thus the time to rest and exercise is seriously insufficient; on the other hand, because of the shortage of sports facilities and conditions, the students' physical education and sports activities is difficult to be guaranteed ${ }^{[3]}$." This shows that the development of school physical education is unsatisfied in reality. Especially in secondary schools, with the increase of academic pressure, all the courses which have nothing to do with the entrance exam have become less important, including physical education. According to information, most middle school only arrange two physical education classes every week, which are often diverted by cultural lesson. However, because the result of physical education has been credited to the total score of senior middle school admissions, the physical education has become extremely important. Many schools organize specialized training team of physical education for the students in grade three, but the practice content of which is limited to the test project. And after the physical education test of senior middle school admissions is over in April, all kinds of the physical education are stopped as well. As physical education like this, not to mention the extracurricular physical activity which is wishy-washy. The low status of the physical education curriculum in reality let students and parents not care about the students' development of physical education. 
Also, students' learning enthusiasm of physical education class is not high. This vicious cycle gradually leads to the marginalized status of current school physical education. The weak position of school physical education stayed unchanged though our country had made great achievement on school physical education since the reform and opening up. Therefore, our colleagues of education and physical education need to work hard sequentially in order to find the deep causes of this situation and solve the problem in essence.

\section{ANALYSIS ON THE FACTORS OF AFFECTING THE STATUS OF SCHOOL PHYSICAL EDUCATION}

\subsection{Poor enforcement of national systems and inef- fective oversight}

Although the national education department pay much attention to school sports in institutional aspect because of comprehensive influence of these factors such as relatively backward development of traditional sports culture and economy, generally weak fitness consciousness and indifference of participating in sports activities of Chinese people, sports with the low level of recognition in society, lack of real understanding of sports of Chinese people, serious lag of the construction of school physical education culture, examination-oriented education system and so on, the enforcement of those rules and regulations is very weak. And with the addition of imperfect supervisory organ and supervision mechanism, some schools didn't obey the rules and regulations of school physical education. In many schools, physical education class just exists literally and, no one shows any interest in the undesirable phenomenon of school physical education such as occupying students' time on extracurricular physical education activities, not much sports funds, and serious shortage of purchasing sports facilities and so on. In addition, national sports system has been criticized because of paying more attention to competitive sports and little attention to social sports and school sports. And the publicity advocate strength and actual economic support of government department giving to school physical education are not enough. In many schools, the lack of physical education funding and shortcoming of physical education facilities directly impact on the teaching of physical education and the practice of students' extracurricular physical education activities, which is also one of the reasons for leading that physical education content is monotonous and students are not interested in physical education class. Furthermore, government departments just having policy guidance but no practical support and strong oversight are primary causes of marginalizing the status of school physical education.

\subsection{People's prejudice towards physical education influenced by traditional culture}

Confucianism had dominated for a long time in Chinese traditional culture. And the concept of paying more attention to intelligence and looking down on physical education seriously affected the status of sports in people's minds. More than one thousand years, Chinese people believe that intelligence development is more important and always practice the principle of mental labour controlling physical labour. That "A good scholar will make an official" is the motto of literary intellectuals who go to school in order to become an official as their lifelong goal. This idea also resulted in that the standard of selecting talents is single and exam-oriented education is popular. The Neo-Confucianism with Confucianism as the core thinks only "static state" is the correct path of sages, while physical exercise with negative sense harms people's physical and mental health. In addition to reading, people who write with pen almost do not engage in any physical activity. Weakness is regarded as a symbol of saint and leisure life. This thought which puts mental training above the physical training and despises the manual labour and physical education has become a social culture. As a result, generation after generation, fragile Chinese elite concentrated on studying the books of sages and took the physical education as activities can be ignored. Influenced by these traditional ideas, the school emphasizing on cultural knowledge class too much, paying attention to student's academic performance and no attention to the cultivation of students' quality in all aspects as well as the cultivation of student's physical quality has become an indisputable fact. Now some people who think that the man engaging in sports is all brawn and simple-minded still despise and ignore sports. They despise the work of physical education teachers and think that physical education is dispensable. Such ideas not getting changed will greatly hinder the improvement of status of school physical education.

\subsection{The disunity of school physical education guiding ideology}

In the process of the development of school physical education, experts and scholars have explored and researched on the guiding ideology of school physical education constantly. Combining with Chinese national conditions and absorbing foreign advanced ideas of school physical education, a variety of views and opinions had been formed, such as the theory of physique as the leading factor which advocates that school physical education should enhance students' physical fitness as the main purpose, the theory of technical ability as the leading factor which advocates that school physical education should make teaching and improving motor skills as the main purpose; the theory of happy physical education which emphasizes 
on fitness and entertainment and pursuits the fun of physical education; the theory of lifelong sports which aims at cultivating sports consciousness and forming the habit of taking physical exercise; the theory of "health first" which advocates that school physical education should make the sustainable development of talents, the healthy development of body and mind, and satisfy the social needs as the main purpose, and the new teaching standards of physical education curriculum and so on. The diversity of teaching thought shows that the recognition of different scholars for the phenomenon, problems and regulars of school physical education are enormously different. These guidelines have their own reasons, but there are some drawbacks at the same time. The disunity of guiding ideology about school physical education result in that front-line teachers do not know what to do in teaching practice. Many places and schools had many misunderstandings and misinterpretations on the guiding ideology, which led to the work of physical education teaching going astray. And there are many incorrect viewpoints and the tendencies such as "the theory of weakening technology", "the theory of students being absolute subjectivity", "the theory of extreme safety", "the theory of reduce the difficulty" and so on. These incorrect viewpoints and the tendencies have penetrated into the real work of school physical education, which make school physical education derail and influence the healthy growth of students from different angles ${ }^{[4]}$. The uncertainty of school physical education guiding ideology confounds the significance and function of school physical education, influences peoples' correct understanding of school sports and weakens the status of school physical education.

\subsection{The generalization of school physical education functions}

In current theoretical circle of school physical education, many specialists and scholars pay more attention to the study on the unessential function than the essential function of physical education, maybe in order to demonstrate the importance of physical education and improve people's understanding of physical education. There are many articles and opinions in some academic journals and textbooks. These usually play role of school physical education to cultivate students' moral quality, or have the function of school physical education to improve the socialization and individualization of students, or play the role of school physical education to cultivate students' ability of "survival", or exert the effect of school physical education on students' mental health, or even become the action of physical education to cultivate students' ability of appreciating beauty and so on ${ }^{[5]}$. And this kind of point of view make the function of school physical education be generalized. In practice, people have ignored the basic functions of school physical education improving students' body physiological function in order to reflect the other functions of school physical education. At the same, this kind of point of view had brought the misconception that school physical education is not important and it is nothing but the supplement and replacement of other disciplines ${ }^{[4]}$ Thus school physical education had carried a heavy burden while the function of school physical education had been generalized. For instance, nowadays, the guiding ideology of "health first" is proposed for the entire school education, which emphasizes the whole school education must make students fully develop in such aspects as moral, brain and body. Only every discipline and every department of school education should conscientiously implement the guiding ideology of "health first", the thought of "health first" could be truly achieved. And the process of achieving "health first" is a systematic project, which needs the effort from family, school and society. School physical education fully undertook the responsibility of students' health and infinitely extended the functions and effects of school physical education on students' health. School physical education takes the impossible task as target; however, it gradually becomes overburdened and steps on the path of formalism. Thus it can be seen that overly generalizing and exaggerating the function of school physical education cannot improve its position and even be doubted by people, thus damaging its status.

\subsection{The factor of physical education teachers}

Physical education teachers are frontline practitioners of school physical education and the dominant players of physical education class. Reflecting on the status of school physical education in education today, the omission of physical education teachers is one of reasons. First of all, a lot of physical education teachers have not been able to recognize the meaning of their lives and the value of educational career and, they cannot play a leading role during their teaching and turn their course to be "a lesson with two kinds of balls". Low responsibility makes the reputation of some physical education teachers bad and also weakens their career position ${ }^{[6]}$. Second, under the background of physical education having been neglected, physical education teachers have been blindly patient and have done nothing. This kind of attitude causes harmful phenomenon, such as school not implementing the policies and systems of physical education, physical education class being diverted, teachers' rights being violated and so on. These all encouraged the thought of looking down on physical education. In addition, in the course of teaching, physical education teachers often force the students to participate in physical education activities by the compulsory measures such as exercise standard and entrance exam. Therefore, students' aspiration, interest and claim toward physical education are ignored, which result in students' revolt on physical education. 


\subsection{The factor of students}

Nowadays, most of the students are only child, who is the most cherished of every family. Their parents and elders spoil them and do not let them do whatever housework and physical activity. And many schools have blindly pursued admissions rate and taken the attitude of "regarding something as important on the lips, ranking it as the second when to do it and, forgetting it when being busy" to school physical education. Although all schools have physical education standard test and require students to reach the standard, but the physical education standard test of many schools are not that strict. If the outstanding students of general knowledge course are not able to reach the standard, the teacher in charge of a class will cut them some slack. So the phenomenon of not reaching the standard of physical education test is virtually non-existent. In addition, because of Chinese large population and weak economic foundation, people face greater living pressure and pressure to compete. Therefore, children are asked to be hard-working and go to a relatively good university under the present social condition and hope of family. And students dare not slack off in their studies. They seize every minute and second to learn. So how is it possible to waste time on inconsequential physical education? Due to the above bad influence from families and society, it finally results in that students for do not like physical education class because of fear of hardship and fatigue. Their enthusiasms are not high in physical education class and afraid of sun, cold wind and dirty. So they are lazy in practices and always dodge the practice with larger intension by the reason of poor health. Some students take physical education class as their recreation time or even stand still. Doing certain strenuous physical activity can improve the physical fitness, which will make the body feel some discomfort. If the student is afraid of difficulty and cannot afford the physiological responses being brought by sports, how can their physical quality be improved and what is the point of having physical education classes? Students are principal part of the physical education class. Their attitude directly impacts on the status of school physical education. However, students escaping and disliking physical education greatly harm the position of physical education.

\section{CONCLUSION}

The weak position of school physical education in school education does not match its importance. The reason for the sports publicity and economic support of country is not enough. And the guiding ideology of school physical education is not clear, because its functions are generalized. Furthermore, there are other factors such as the traditional culture, exam-oriented education, living pressure, and the sense of responsi- bility among part of physical education teachers is low. These factors mutually influence and interweave with each other, which increase the difficulty to solve the problem. In order to improve the status of school physical education, governments and education departments should increase support and make people understand the importance of school physical education through publicizing, providing fund to meet the need of field and facilities and the equipment of teachers, and improving teachers' professional ability and moral accomplishment. Under the strong support of country and the joint efforts of physical educators, the status of school physical education will be improved soon.

\section{REFERENCES}

[1] Limin Xiang. 2012. Sociologic thoughts on transition of physical education guidance ideology in schools in our country at modern age. Journal of Xian institute of Physical Education, 22(6): 104-107.

[2] The progposal of implementing the guarantee of primary and secondary school students' time of physical education every day. www.schoolsports.com.cn/info/info.asp/info_ID $=4543$

[3] The progposal of strengthening teenagers' physical education in order to improve teenagers' physique. www.moe.edu.cn/publicfiles/business/htmlfiles/moe/ moe 1778/200710/27692.html

[4] Pingbo Huang, Ping w. \& Yimo Yang. 2008. On students physique continuously decline influenced by the variability in school physical education. Journal of Kaili University, 26(3): 80-84.

[5] Yongmei Gong. 2005. Study on the status of physical education in school. Shandong Sports Science\& Technology, 27(2): 75-77.

[6] Yu Wang. 2008. The unbearable lightness of being---Reflection on current status of physical education in China under the domain of life education. Journal of Wuhan Institute of Physical Education, 42 (2): 93-96

[7] Guoqiang Peng \& Xianlin Xiang. 2013. The evolution and thinking of PE teaching ideology in 60th anniversary of new China. Journal of TUS, 24(3): 205-208.

[8] Haoran Li. 2012. Developing school sports on students' development oriented. Journal of Nanjing Institute of Physical Education (Natural Science), 11(1): 94-96.

[9] Qidi LI, Weide Shao, \& Jian Wang. 2013. Gardiner's education theory and its inspirations to school physical education reform and development in China. Journal of Physical Education, 20(6):70-73.

[10] Weide Shao, Yan Ping, Qidi LI \& Jianhua Hu. 2013. Influence research on the development of school physical education in China from Dewey's educational theory. Journal of Physical Education, 36(10): 93-99.

[11] Weide Shao, Yan Ping, Qidi LI \& Jianhua Hu. 2015 Review on the generalization of school physical education function. Journal of Capital University of Physical Education and sports, 27(2):134-136.

12] Xiaoli Huang, Yuqiang Jin, Liangqiu Lu \& Kexing Li. 2014. Rational inspections of the value of school sports. Journal of Guangzhou Sport University, 34(6): 11-15. 